Review

\title{
Novel Therapeutic Opportunities in Neoadjuvant Setting in Urothelial Cancers: A New Horizon Opened by Molecular Classification and Immune Checkpoint Inhibitors
}

\author{
Maria Lucia Iacovino ${ }^{1,+}$, Chiara Carmen Miceli ${ }^{1,+}$, Marco De Felice ${ }^{1,+}$, Biagio Barone ${ }^{2}$ D, Luca Pompella ${ }^{1}$, \\ Francesco Chiancone $^{3}{ }^{\mathbb{D}}$, Erika Di Zazzo ${ }^{4} \mathbb{D}$, Giuseppe Tirino $^{1}{ }^{1}$, Carminia Maria Della Corte ${ }^{1}$, Ciro Imbimbo ${ }^{2}$, \\ Ferdinando De Vita ${ }^{1}$ and Felice Crocetto ${ }^{2, * \mathbb{D}}$
}

check for updates

Citation: Iacovino, M.L.; Miceli, C.C.; De Felice, M.; Barone, B.; Pompella, L.; Chiancone, F.; Di Zazzo, E.; Tirino, G.; Della Corte, C.M.; Imbimbo, C.; et al. Novel Therapeutic Opportunities in Neoadjuvant Setting in Urothelial Cancers: A New Horizon Opened by Molecular Classification and Immune Checkpoint Inhibitors. Int. J. Mol. Sci. 2022, 23, 1133. https://doi.org/ $10.3390 /$ ijms23031133

Academic Editors: Niall M. Corcoran and Giuseppe Lucarelli

Received: 22 December 2021

Accepted: 18 January 2022

Published: 20 January 2022

Publisher's Note: MDPI stays neutral with regard to jurisdictional claims in published maps and institutional affiliations.

Copyright: (C) 2022 by the authors. Licensee MDPI, Basel, Switzerland. This article is an open access article distributed under the terms and conditions of the Creative Commons Attribution (CC BY) license (https:// creativecommons.org/licenses/by/ $4.0 /)$.
1 Department of Precision Medicine, Medical Oncology, University of Campania Luigi Vanvitelli, Via Sergio Pansini 5, 80131 Naples, Italy; marialucia.iacovino@unicampania.it (M.L.I.); chiaracarmen.miceli@unicampania.it (C.C.M.); marco.defelice@unicampania.it (M.D.F.); luca.pompella@unicampania.it (L.P.); giuseppe.tirino@unicampania.it (G.T.);

carminiamaria.dellacorte@unicampania.it (C.M.D.C.); ferdinando.devita@unicampania.it (F.D.V.)

2 Department of Neurosciences, Reproductive Sciences and Odontostomatology, University of Naples "Federico II", 80131 Naples, Italy; biagio.barone@unina.it (B.B.); ciro.imbimbo@unina.it (C.I.)

3 Department of Urology, AORN “A.Cardarelli”, 80131 Naples, Italy; francescok86@gmail.com

4 Department of Medicine and Health Sciences "V. Tiberio", University of Molise, UOC Laboratorio Analisi P.O. “A. Cardarelli", 86100 Campobasso, Italy; erika.dizazzo@unimol.it

* Correspondence: felice.crocetto@unina.it

+ These authors contributed equally to this work.

Abstract: Muscle invasive bladder cancer (MIBC) is a widespread malignancy with a worse prognosis often related to a late diagnosis. For early-stage MIBC pts, a multidisciplinary approach is mandatory to evaluate the timing of neoadjuvant chemotherapy (NAC) and surgery. The current standard therapy is platinum-based NAC (MVAC-methotrexate, vinblastine, doxorubicin, and cisplatin or Platinum-Gemcitabine regimens) followed by radical cystectomy (RC) with lymphadenectomy. However, preliminary data from Vesper trial highlighted that dose-dense NAC MVAC is endowed with a good pathological response but shows low tolerability. In the last few years, translational-based research approaches have identified several candidate biomarkers of NAC esponsiveness, such as ERCC2, ERBB2, or DNA damage response (DDR) gene alterations. Moreover, the recent consensus MIBC molecular classification identified six molecular subtypes, characterized by different sensitivity to chemo- or targeted or immunotherapy, that could open a novel procedure for patient selection and also for neoadjuvant therapies. The Italian PURE-01 phase II Trial extended data on efficacy and resistance to Immune Checkpoint Inhibitors (ICIs) in this setting. In this review, we summarize the most relevant literature data supporting NAC use in MIBC, focusing on novel therapeutic strategies such as immunotherapy, considering the better patient stratification and selection emerging from novel molecular classification.

Keywords: bladder cancer; urothelial cancers; neoadjuvant chemotherapy; Immune Checkpoint Inhibitors; molecular classification of muscle-invasive bladder cancer; muscle-invasive bladder cancer

\section{Introduction}

Urothelial bladder cancer (BC) accounts for an estimated 500,000 new cases and 200,000 deaths worldwide, with more than 25,500 new cases in Italy estimated in 2020 [1].

$\mathrm{BC}$ is classified in nonmuscle invasive (NMIBC) (75\% of diagnoses) [2] and muscleinvasive bladder cancer (MIBC). MIBC is characterized by pelvic and/or iliac lymph node metastases in a great percentage of patients (pts) and sometimes by distant metastasis, such as bone lesions [3]. Therefore, especially in MIBC, accurate staging is mandatory to apply the appropriate therapeutic strategy [4]. 
Since the 1980s, when cisplatin-based chemotherapy (CT) was introduced for MIBC treatment, only few steps forward have been taken. Although international guidelines recommend neoadjuvant chemotherapy (NAC) with cisplatin-based schemes, less than $20 \%$ of MIBC pts receive this treatment in clinical practice [5,6]. Firstly, $50 \%$ of subjects are unfit for CT, and carboplatin is applied for a subset of them [7]. Secondly, clinical and pathological predictive markers to identify pts eligible for NAC therapy are not available yet [8]. To improve clinical MIBC outcome, CT has been proposed in association with locoregional treatments such as surgery (radical cystectomy- RC) and/or radiotherapy (RT).

In recent years, translational-based research approaches have made great efforts in building up the concept of personalized medicine for oncology pts, suggesting new prognostic and predictive biomarkers; novel targets, and introducing new therapies, such as immunotherapy-based ones. DNA and RNA sequencing of BC specimens showed the complex genetic heterogeneity of $\mathrm{BC}$ and identified specific profiles based on the type and frequency of mutations, on gene copy numbers and on the methylation patterns that could be helpful to define patient prognosis and sensitivity to specific treatments [9]. Tumor biology studies could be useful to discover novel early-stage disease and tumor progression markers. Specifically, MIBC harbors a higher overall mutation rate and number of chromosomal aberrations than NMIBC, mainly involving the activation of prosurvival pathways such as p53, Rb, Pi3k-mTor, and RAS [10].

\section{Molecular Classifications of MIBC: A Yet Uncomplete Picture}

$\mathrm{BC}$ is a very complex disease, both from a clinical and biological point of view. In our opinion, molecular biology represents the key to reveal the possible Achilles' heel in BC and to identify novel targets in neoadjuvant as well as advanced settings.

In 2014, the first comprehensive bulk multiomics characterization of MIBC was carried out on The Cancer Genome Atlas (TCGA) samples [9]. Whole-genome and RNA-sequencing of 131 chemo-naïve MIBC was performed to detect somatic mutation, copy number aberrations (CNA), and transcriptomic subtypes. The analysis revealed 32 significantly mutated genes [SMGs] (9 of them identified for the first time in MIBC) and the majority (93\%) were involved in cell cycle regulation, chromatin structure modification $(89 \%)$, and kinase signaling pathways $(72 \%)$. The most relevant mutated genes were involved in the PI3K-AKT-mTOR pathway ( $42 \%$ of tumors-PIK3CA, $17 \%$; TSC1/2, 9\%; AKT3, 10\%) and RTK/RAS pathways (FGFR3 activation, 17\%; EGFR amplification, 9\%; ERBB3 mutations, 6\%; ERBB2 mutations or amplifications, 9\%). It is interesting to note that almost $69 \%$ of the altered genes involved in kinase signaling pathways could be targetable. On the other side-and complementary to findings from whole-genome sequencing-RNA-sequencing identified at least 4 transcriptomic subtypes; among them, the attention was focused on Cluster 1 (Papillary-like), which is characterized by FGFR3 gene aberrations (mutations, amplifications, rearrangements), potentially targetable with FGFR3 inhibitors, and Cluster 3 (basal/squamouslike), similar to basal-like breast cancers.

Three years later, TCGA research network increased MIBC's sample size to $412 \mathrm{pts}$ [11] and provided the most accurate bulk molecular classification currently available of MIBC with a multiomics approach (Whole-genome sequencing, Copy number analysis, DNA methylation analysis, mRNA-sequencing, noncoding RNA-sequencing). The analysis showed 58 SMGs (34 novel vs. analysis performed in 2014) and identified five mutational signatures (the most relevant was related to APOBEC-a and APOBEC- $b$, accounting for $67 \%$ of tumors), with a different pts survival. The RNA-sequencing approach revealed five different subtypes. Integration of the results achieved with the other platform allowed the correlation among each subtype with possible therapeutic targets and survival information.

Of note, three subtypes called "luminal" (due to the expression of markers such as KRT20, GATA3, and FOXA1) are distinct:

- "Luminal-papillary" (35\%): Characterized by papillary morphology, FGFR3 mutations/amplifications/fusions, activation of Sonic-Hedgehog pathways, low risk of progression, and a low NAC response rate. The relative high frequency of FGFR3 gene 
aberrations suggested that this subtype could be targetable with FGFR3 (or PAN-FGFR) inhibitors, such as Erdafitinib. This drug has already been tested in a second-line setting in the phase II BLC2001 Trial [12] and was approved by the FDA in April 2019 for treatment of advanced BC with FGFR3 (or FGFR2) genetic alterations. A confirmatory phase III trial is currently ongoing (NCT03390504) in a second/third-line setting. This trial aims to compare Erdafitinib with standard chemotherapy (Docetaxel, Vinflunine) or immunotherapy (pembrolizumab, second line) in pts harboring FGFR aberrations.

- "Luminal-infiltrated" (19\%): Characterized by low tumor purity with high immune/ stromal infiltration and high expression of PDL1 and CTLA4. It has been speculated that this subtype could respond to immune checkpoint inhibition therapy, and could show no or few responses to standard platinum-based CT.

- "Luminal-subtype" (6\%): Characterized by high expression levels of uroplakines, KRT20, and SNX31. Targets for this subtype have not been discovered yet.

Other subtypes are as follows:

- "Basal/Squamous" subtype (35\%): mostly observed in women than men. It shows squamous differentiation (basal keratin markers) with high PDL1 and CTLA4 immune/stromal populations. It has been speculated that this subtype could respond well to both platinum-based CT and immunotherapy.

- The "neuronal" subtype (5\%), the last identified one (a "novelty" of this classification): It expresses both neuroendocrine and neuronal genes with a high cell-cycle signature. This MIBC type does not exhibit the typical morphology of neuroendocrine tumors and RNA-seq or specific immunohistochemistry staining could identify it. In this case, the best therapeutic option could be-similar to other high-grade neuroendocrine tumors-a combination of platinum and etoposide.

A consensus for the transcriptomic classification recapitulating all published data, similar to that performed for colorectal cancer [13], was published in 2020 in the European Urology Journal [14]. The classification identified 6 consensus MIBCs: Luminalpapillary (LumP), Luminal-non-Specified (LumNS), Luminal-Unstable (LumU), Stromarich, Basal/Squamous (Ba/Sq), and Neuroendocrine-like (NE-like). Although this classification shows partial overlapping with the TCGA transcriptional subtypes, it adds clinical and molecular data, and represents a starting point for the design of new generation molecular-oriented clinical trials.

\section{Neoadjuvant Chemotherapy (NAC): The State of Art}

\subsection{Clinical Staging}

Clinical management of BC pts is complex and not well-standardized: multiple options could be selected to reach the effective and appropriate treatments for each patient [15]. $\mathrm{BC}$ is usually detected after the clinical observation of hematuria. Cystoscopy, showing high sensitivity and specificity up to $95 \%$ and $100 \%$, and high positive and negative predictive value, represents the gold standard for diagnosis and follow-up. However, flat and papillary lesions could be missed and nodal/extravesical involvement could not be assessed [16,17]. Considering that TNM staging persists as an independent prognostic factor with a 5 -years specific survival rate ranging from $96 \%$ for carcinoma in situ, to $36 \%$ for loco-regional disease, and 10\% for metastatic disease, diagnostic imaging is pivotal in clinical practice for appropriate staging and for the therapeutic algorithm $[18,19]$.

The latest American College of Radiology Appropriateness Criteria (ACRAC) report stated that pretreatment staging of MIBC should include imaging of the urothelial upper tract with Magnetic Resonance Imaging (MRI) of the pelvis for local staging or Computerized Tomography (CT) of the abdomen and pelvis without and with contrast to assess synchronous lesions of the urothelium and abdominal organs, plus imaging of the chest for excluding lung metastases [20].

However, morphology assessment showed low sensitivity and specificity in detecting pathological lymph nodes due to the occurrence of false positive results, because the main criteria used to deem a lymph node as suspicious for metastatic disease is its size. 
Current recommendations suggest a major diameter cut-off $>8 \mathrm{~mm}$ for pelvic lymph nodes and $>1 \mathrm{~cm}$ for retroperitoneal ones [21]. Functional evaluation with diffusion-weighted and dynamic MRI sequences improves our ability to perform nodal staging compared with conventional MRI and could optimize treatment response assessment, distinguishing early responders to NAC [22-24]. By the way, Nguyen et al. developed a model to characterize the $\mathrm{BC}$ microcirculatory changes and, by comparing MR images acquired at the beginning and at mid-NAC, observed significant differences between responders and nonresponders [25].

Assessing the importance of functional diagnostics, the latest ACRAC highlights that 18-Fluorodeoxyglucose (FDG) Positron Emission Tomography (PET)/CT could be appropriate for BC staging. This technique shows high sensitivity for preoperative lymph node staging and extravesical involvement, particularly for sub-centimetric nodes, where the traditional size criterion cannot be helpful [15]. In addition, several data suggest a potential role of 18-FDG PET/CT and PERCIST Criteria for restaging and response evaluation of MIBC. Progression-free survival (PFS) was significantly higher in pts with negative scans versus those with persistence of disease after NAC, and overall survival (OS) significantly reduced in the case of positive scan [26].

\subsection{Neoadjuvant $C T$}

Nowadays, the standard therapy for non-metastatic MIBC pts consists of platinumbased NAC, followed by RC and bilateral pelvic lymphadenectomy. RC alone, in fact, is associated with high recurrence rates and poor prognosis (5-years OS up to 50\%) [27]. Chemotherapy administered in a neoadjuvant setting shows some advantages: the ability to deliver effective systemic therapy for micro-metastatic disease; improvement of direct drug delivery into the bladder and to surrounding lymphatic vessels and lymph nodes; and increases the probability of a better performance status of naïve pts for major surgical procedure [28]. In this setting, MIBC pts treated with NAC showed a downgrade of disease and an overall improved prognosis. A recent metanalysis demonstrated a $5 \%$ OS and a $9 \%$ disease-free survival (DFS) improvement at 5 years [29]. However, SWOG and EORTC studies reported a high-grade toxicity in more than one patient out of three, without a significant OS improvement in MIBC pts. Thus, the selection of pts with clinical T3 and T4 that could benefit from NAC avoiding toxicity is a challenge for the future [29]. MIBC could be further divided into low- and high-risk groups, including >cT3b disease, presence of hydroureteronephrosis, lymphovascular invasion, or more aggressive variant histologies such as squamous, sarcomatoid, or neuroendocrine features [30].

The NAC regimen for MIBC treatment has not been modified over the years. Firstly, a single-agent platinum-based chemotherapy was proposed that was immediately discarded for lack of benefit (hazard-ratio $(H R)=1.15, p=0.264$ ) [31]. Therefore, in four following perspective trials, only platinum-based multiagent regimens were tested. However, all studies showed low accrual rate and the results obtained were not statistical significant to demonstrate a benefit over surgery upfront [32-36]. Subsequently, the Advanced Bladder Cancer meta-analysis Collaboration group combined the results of these trials in a metanalysis and observed that platinum-based regimens significantly improved OS (combined HR_0.86, $p=0.003$ ), with a risk of death decreased by $13 \%$, with an absolute benefit equal to $5 \%$ and an absolute DFS improved by $9 \%$ at 5 years, independently of the type of local treatment, and in all subgroups of pts. This meta-analysis also assessed that the evidence of ypT0 stage after RC was a valid surrogate marker of oncological outcomes improvement [31].

MVAC (methotrexate, vinblastine, doxorubicin, and cisplatin) in a high-dose-intensity schedule (every fourteen days plus granulocyte colony stimulating factor), for three cycles in six weeks and minimizing the interval between diagnosis and surgery, represents the first multiagents regimen studied. Interestingly, about half of the pts achieved pathological complete response (pCR) or a downstaging to NMIBC, and $82 \%$ of pts with $\mathrm{cN} 1$ disease before cystectomy were $\mathrm{pN} 0$ after surgery $[37,38]$. However, as previously pointed out, one of the issues in the multidisciplinary management of MIBC is the correct preoperative 
staging of lymph nodes. Thus, these conclusions should be interpreted with caution for the risk of radiological overstaging.

Over the past years, Gemcitabine and cisplatin (GC) combination has been evaluated as a possible alternative to MVAC regimen. One prospective randomized phase III trial including locally advanced (T4b, N2, N3) or metastatic MIBC, comparing GC with MVAC, demonstrated that GC has noninferior oncological outcomes and a safer toxicity profile than MVAC [39].

Retrospective trials offered variable results. One large retrospective analysis of $212 \mathrm{pts}$ showed similar results in terms of efficacy and safety [40]; another retrospective review of 319 pts affected by urothelial cancer who received neoadjuvant chemotherapy and cystectomy conducted by Zargar et al. [41] showed better results with a dose-dense (dd) MVAC regimen in terms of local control, pathological complete response (ypT0N0), compared with the GC regimen ( $28 \%$ vs. $15 \%, p=0.005)$.

The French GETUG/AFU V05 VESPER [42] trial was the first prospective randomized phase III controlled trial comparing the efficacy of dd-MVAC and GC in perioperative setting (before or after RC). The primary endpoint was PFS at 3 years. Secondary endpoints were response rate (RR) according to RECIST 1.1 criteria (in neoadjuvant setting), OS and time to progression (TTP), and chemotherapy toxicity.

First results on pathological responses and chemotherapy toxicity were published early this year [43]. A higher local control rate ( $\mathrm{pCR}$, tumor downstaging, or organ confined) was observed in the dd-MVAC arm $(p=0.021)$. Hematological toxicities were equally reported in both arms, but severe anemia was most frequent in the dd-MVAC arm $(p<0.001)$. Other common adverse events were asthenia and gastrointestinal disorders (nausea/vomiting), more frequently observed in the dd-MVAC arm.

Recently, data on PFS were presented [42], showing a three-years PFS of $64 \%$ in the dd-MVAC arm vs. $56 \%$ of GC (HR $=0.77 ; 95 \%$ CI $0.57-1.02 ; p=0.066)$ considering the entirety of the perioperative setting. Further, considering the neoadjuvant group separately, three-years PFS was significantly higher for the dd-MVAC arm. Additionally, TTP was improved, and this met statistical significance (3-years rate: $69 \%$ vs. $58 \%, \mathrm{HR}=0.68$ (95\% CI 0.50-0.93), $p=0.014$ ). dd-MVAC arm also improved OS in the neoadjuvant group $(\mathrm{HR}=0.66 ; 95 \%$ CI 0.47-0.92).

Some relevant issues need to be discussed when considering neoadjuvant CT for MIBC.

Table 1 summarizes the main trials evaluating neoadjuvant chemotherapy for $\mathrm{BC}$.

\subsection{How Many Pts Are Fit for Cisplatin?}

Cisplatin can be replaced by carboplatin according to the integrated management clinical approach in other cancers, but for this setting, we still do not have enough data to recommend carboplatin-based regimens for NAC in BC $[5,6]$. A consensus definition of pts with metastatic urothelial carcinoma that unfit for cisplatin-based chemotherapy was released in 2011 among BC experts. Pts "unfit" for cisplatin were defined with at least one of the following criteria: performance status $>1$; glomerular filtration rate $<60 \mathrm{~mL} / \mathrm{min}$; grade $>2$ audiometric loss; peripheral neuropathy and New York Heart Association (NYHA) class III heart failure [7]. It appears clear that the probability of ineligibility to cis-platin increases with age because, by the Cockroft-Gault equation for measurement of re-nal function, more than $40 \%$ of pts with an age over 70 years are ineligible, considering that the average age of $\mathrm{BC}$ is around 70 years. Many randomized trials have shown that carboplatin-based therapy is inferior compared with cisplatin in terms of OS and PCR; that is why some authors proposed a more tolerated reduced dose of cisplatin $50 \mathrm{mg} / \mathrm{m}^{2}$ : a sequential ifosfamide, doxorubicin, and gemcitabine followed by reduced-dose cisplatin, gemcitabine, and ifosfamide resulted in similar oncological outcomes, with a pathological downstaging to pT1N0 disease or lower occurring in $50 \%$ of pts who underwent RC [44,45] Despite these data, nowadays in cisplatinineligible pts, the standard of care re-mains to be upfront $\mathrm{RC}$, unfortunately with a higher risk of systemic relapse [5,6]. We speculate that other biological agents such as neoadjuvant immune checkpoint inhibitors (ICIs) could later be the solution for this subset of pts. 
Table 1. Summary of trials using chemotherapy in neoadjuvant setting.

\begin{tabular}{|c|c|c|c|c|c|c|c|c|}
\hline Trial Name & Phase & NAC & Regimen & Elegible Pts & Sample Size & $\mathrm{pCR}$ & DFS & OS \\
\hline $\begin{array}{l}\text { Wallace et al., } 1991+ \\
\text { Raghavan et al., } 1991\end{array}$ & $\begin{array}{c}\text { Randomized } \\
\text { clinical trial }\end{array}$ & $\begin{array}{c}\text { Cisplatin } \rightarrow \text { Cystectomy } \\
\text { vs. RT }\end{array}$ & // & Elegible for CDDP & 255 & // & $/ /$ & $\begin{array}{l}\text { No difference between } \\
\text { two arms }\end{array}$ \\
\hline Martinez-Pinerio et al., 1995 & $\begin{array}{l}\text { Randomized } \\
\text { clinical trial }\end{array}$ & $\begin{array}{l}\text { Cisplatin } \rightarrow \text { Cystectomy } \\
\text { vs. Cystectomy }\end{array}$ & // & Elegible for CDDP & 121 & $/ /$ & $/ /$ & $\begin{array}{l}\text { No difference between } \\
\text { two arms }\end{array}$ \\
\hline EORTC/MRC BA06, 1999 & $\begin{array}{l}\text { Randomized } \\
\text { clinical trial }\end{array}$ & $\begin{array}{c}\mathrm{CMV} \rightarrow \text { Cystectomy/RT } \\
\text { vs. Cystectomy/RT }\end{array}$ & // & Elegible for CDDP & 976 & // & $/ /$ & $\begin{array}{l}5 \text { y OS } 49 \% \text { in CMV group } \\
\text { vs. } 43 \% \text { in Cystectomy } \\
\text { group ( } p \text {-value } 0.048)\end{array}$ \\
\hline $\begin{array}{l}\text { Bassi P. et al. } \\
\text { (GUONE), } 1999\end{array}$ & $\begin{array}{l}\text { Randomized } \\
\text { clinical trial }\end{array}$ & $\begin{array}{l}\text { M-VAC } \rightarrow \text { Cystectomy } \\
\text { vs. Cystectomy }\end{array}$ & 4 Cycles q $28 \mathrm{M}$-VAC & Elegible for CDDP & 206 & $/ /$ & $/ /$ & $\begin{array}{l}\text { No difference between } \\
\text { two arms }\end{array}$ \\
\hline $\begin{array}{l}\text { GISTV (Italian Bladder } \\
\text { Cancer Group), } 1996\end{array}$ & $\begin{array}{l}\text { Randomized } \\
\text { clinical trial }\end{array}$ & $\begin{array}{l}\text { M-VEC } \rightarrow \text { Cystectomy } \\
\text { vs. Cystectomy }\end{array}$ & 3 cycles MVEC & Elegible for CDDP & 171 & $24 \%$ & // & $\begin{array}{l}\text { No difference between } \\
\text { two arms }\end{array}$ \\
\hline H. von der Maase et al., 2000 & $\begin{array}{l}\text { Randomized } \\
\text { clinical trial }\end{array}$ & $\begin{array}{l}\text { CDDP + } \\
\text { Gem } \rightarrow \text { cystectomy vs. } \\
\text { MVAC } \rightarrow \text { Cystectomy }\end{array}$ & $\begin{array}{l}\text { Max } 6 \text { Cycles CDDP + } \\
\text { Gem q28 or MVAC q28 }\end{array}$ & Elegible for CDDP & 405 & $\begin{array}{l}12.5 \% \text { in } \mathrm{CDDP}+\mathrm{Gem} \\
\text { group vs. } 11.9 \% \text { in } \\
\text { MVAC group }\end{array}$ & $\begin{array}{l}\text { mDFS } 7.4 \mathrm{~m} \text { in } \\
\text { both groups }\end{array}$ & $\begin{array}{l}\text { mOS } 13.8 \mathrm{~m} \text { vs. } 14.8 \mathrm{~m} \\
\text { (p-value } 0.75) \text {. CDDP + } \\
\text { Gem was superior in } \\
\text { risk-benefit ratio with no } \\
\text { difference in OS }\end{array}$ \\
\hline $\begin{array}{c}\text { Sherif A. } \\
\text { (NORDIC I-II), } 2004\end{array}$ & $\begin{array}{l}\text { Randomized } \\
\text { clinical trial }\end{array}$ & $\begin{array}{c}\text { ADM + CDDP + } \\
\text { RT } \rightarrow \text { cystectomy vs. } \\
\text { RT + Cistectomy MTX } \\
+ \text { CDDP } \rightarrow \text { cystectomy } \\
\text { vs. Cystectomy }\end{array}$ & 3 cycles q 28 & Elegible for CDDP & 620 & // & $/ /$ & $\begin{array}{l}5 \text { y OS } 56 \% \text { in NAC group } \\
\text { vs. } 48 \% \text { in CYstectomy } \\
\text { group ( } p \text {-value } 0.045)\end{array}$ \\
\hline Osman et al., 2014 & $\begin{array}{l}\text { Randomized } \\
\text { clinical trial }\end{array}$ & $\begin{array}{c}\text { CDDP + } \\
\text { Gem } \rightarrow \text { Cystectomy } \\
\text { vs. Cystectomy }\end{array}$ & 3 cycles q21 & Elegible for CDDP & 60 & $35 \%$ & $\begin{array}{l}3 \text { y DFS } 57 \% \text { in NAC } \\
\text { group vs. } 43 \% \text { in } \\
\text { Cystectomy group }\end{array}$ & $\begin{array}{c}3 \mathrm{y} \text { OS } 60 \% \text { in NAC group } \\
\text { vs. } 50 \% \text { in } \\
\text { Cystectomy group }\end{array}$ \\
\hline $\begin{array}{l}\text { Kitamura et al., } \\
2014 \text { JCOG0209 }\end{array}$ & $\begin{array}{l}\text { Randomized } \\
\text { clinical trial }\end{array}$ & $\begin{array}{l}\text { M-VAC } \rightarrow \text { Cystectomy } \\
\text { vs. Cystectomy }\end{array}$ & 2 cycles M-VAC q 28 & Elegible for CDDP & 130 & $34 \%$ & $\begin{array}{l}99 \mathrm{~m} \text { in NAC group vs. } \\
78 \mathrm{~m} \text { in } \\
\text { cystectomy group }\end{array}$ & $\begin{array}{l}5 \text { y OS } 72.3 \% \text { in NAC } \\
\text { group vs. } 62.4 \% \text { in } \\
\text { Cystectomy group }\end{array}$ \\
\hline $\begin{array}{l}\text { GETUG/AFU V05 } \\
\text { VESPER (2021) }\end{array}$ & $\begin{array}{l}\text { Randomized } \\
\text { clinical trial }\end{array}$ & $\begin{array}{c}\text { ddMVAC } \rightarrow \text { Cystectomy } \\
\text { vs. CDDP + } \\
\text { Gem } \rightarrow \text { Cystectomy }\end{array}$ & $\begin{array}{c}6 \text { cycles ddMVAC q14 } \\
\text { vs. } 4 \text { cycles CDDP + } \\
\text { Gem q21 }\end{array}$ & Elegible for CDDP & $\begin{array}{c}437 \text { in } \\
\text { neoadjuvant setting }\end{array}$ & $\begin{array}{l}42 \% \text { in ddMVAC } \\
\text { group vs. } 36 \% \text { in } \\
\text { CDDP + Gem group } \\
(p \text {-value } 0.021)\end{array}$ & $\begin{array}{c}3 \text { y PFS } 66 \% \text { dd } \\
\text { MVAC vs. } 56 \% \text { CDDP } \\
+ \text { Gem ( } p \text {-value } 0.025)\end{array}$ & $\begin{array}{l}\text { OS data are not yet ready, } \\
\text { but are expected to } \\
\text { confirm these results. }\end{array}$ \\
\hline
\end{tabular}

Abbreviations: NAC—neoadjuvant chemotherapy; pts—patients; pCR—pathological complete response; DFS—disease-free survival; OS—overall survival; RT—radiotherapy; CDDP_ cisplatin; M-VAC — methotrexate, vinblastine sulfate, adriamycin, and cisplatin; CMV—cisplatin methotrexate, vinblastine sulfate; MVEC — methotrexate, vinblastine, epirubicin, and cisplatin; ADM-Adriamycin; MTX—-methotrexate; ddMAVC—dose-dense M-VAC. 


\subsection{Which Is the Right Timing for Surgery?}

It is important to not delay surgery, especially in pts that will not respond, so treatment delays could lead to an increased difficulty of the surgical procedure due to perioperative morbidity. In fact, actually one of the main reasons for low uptake of NAC is the risk in increasing the timing between diagnosis of MIBC and surgical treatment because such a delay has been shown to negatively impact oncological outcomes. This statement is based on a meta-analysis pooling 12 retrospective and 1 prospective trials that failed to show a linear relationship between delay and prognosis, but the majority confirmed that a longer delay was associated with worse outcomes, with a window of opportunity of less than 12 weeks from the diagnosis [46]. Nevertheless, a Dutch trial did not show any difference in clinical outcomes after adjusting for confounding variables between delayed RC more than 3 months from the diagnosis and traditional RC, so optimal timing of cystectomy is still far to be defined. It is worthy to underline that, different from primary MIBC, a secondary MIBC is not likely to respond to NAC and should always be considered for upfront total cystectomy [47].

\subsection{Are There More Complications for Surgery after Neoadjuvant CT?}

Although the administration of neoadjuvant CT increased MIBC overall survival, only $15 \%$ of pts who underwent RC received neoadjuvant CT [48-51]. Among the reasons that could explain this phenomenon, concerns regarding detrimental perioperative complications could have limited this approach in eligible pts. As reported by Gandaglia et al., the use of neoadjuvant chemotherapy is, however, not associated with higher perioperative morbidity and mortality. Indeed, no significant differences were observed in rates of complications, readmissions, and mortality among pts who received neoadjuvant CT and RC compared with RC alone [52]. A similar result was obtained by Tyson et al., who reported no difference in perioperative complication at surgery for pts receiving neoadjuvant CT, although a higher rate of peripheral nerve deficits (mostly related to the use of cisplatinbased chemotherapy) was found [53]. Moreover, neoadjuvant CT was not associated with increased operative time or wound infection rate and could aid the surgeon in converting unresectable disease to operable tumor burden [54]. Considering the new adjuvant CTs such as Atezolizumab and Pembrolizumab, the results were similar, confirming the tolerability and the absence of impact in the surgical setting, as reported in the safety results from ABACUS trial [55] and PURE-01 trial [56]. In particular, the most common complications were limited to minor grade complications as fever (35\%) and ileus (21\%), while major grade complications (Clavien Dindo $>3 \mathrm{a}$ ) were consistent with other pts who received $\mathrm{RC}$ alone $(20-30 \%)$ [56].

\subsection{How to Manage Variant BC?}

Another unmet need about MIBC is how to manage variant BC. As shown in EAU-ESMO consensus statements, BC with small-cell neuroendocrine variant should be treated with neoadjuvant chemotherapy followed by consolidating local therapy; muscle-invasive puresquamous cell carcinoma and pure-adenocarcinoma of the bladder should be treated with primary RC and lymphadenectomy [5]. In a subgroup analysis from the randomized controlled trial, SWOG-8710 pts with mixed histology-squamous or glandular-were seen to have a survival benefit from NAC compared with primary RC (HR 0.46; 95\% CI 0.25-0.87; $p=0.02$ ) [57], consistent with a previous report that showed similar oncological outcomes for pts with pure urothelial BC and variant histology treated with NAC, with a higher rate of pathological downstaging too [58]. For micropapillary histology, authors reported pathological complete response rate after NAC ranging from $11 \%$ to $55 \%$ without significantly affecting relapse-free survival (RFS) (HR 1.23; 95\% CI 0.52-2.93; $p=0.6$ ) or OS (HR 1.35; 95\% CI 0.98-1.86; $p=0.1$ ) [59]. Plasmocytoid variant is very rare and aggressive, but data are immature for considering NAC [60]. Moreover, urachal carcinoma has been shown to have no benefit with cisplatin-based neoadjuvant chemotherapy [61]. 


\section{Neoadjuvant Immunotherapy}

Tumor cells evade immunosurveillance and progress towards a malignant behavior through different mechanisms [62]. Immune checkpoint inhibitors (ICIs) reinvigorate antitumor immune responses by interrupting coinhibitory signaling pathways and promoting immune-mediated tumor cells elimination. Monoclonal antibodies blocking the immune checkpoint through PD-1, PD-L1, or CTLA-4 have demonstrated impressive clinical activities against several tumors $[63,64]$.

PD-1 on T cells is activated by its ligand PD-L1 expressed by diverse cell types. PD-L1/PD-1 binding leads to T cell response inhibition. Under physiological conditions, PD-1 expression on T cells is induced by TCR signaling and its expression decreases to basal levels upon antigen clearance. Persistent antigen stimulation in the tumor microenvironment can lead to constitutively high PD-1 expression [65]. CTLA-4 expression and function are linked to $\mathrm{T}$ cell activation, reducing TCR signaling by competing with the costimulatory molecule CD28 for the B7 ligands (B7-1/CD80 and B7-2/CD86) $[66,67]$.

ICIs have been used for metastatic $B C$ treatment as a second-line therapeutic approach after platinum-therapy failure [64] or as first-line strategy for cisplatin-ineligible pts [68]. In addition, the anti-PDL1 avelumab has been approved in maintenance setting after first-line chemotherapy [69].

More recently, ICIs have shown promising results in MIBC preoperative setting, in terms of both pathological response and safety profile. Several phase II trials highlighted the potential role of immunotherapy as a valuable strategy for neoadjuvant therapy, especially in cisplatin-unfit pts [70].

PURE-01 [56] was the first open label, single-arm, phase II study evaluating the neoadjuvant pembrolizumab efficacy in MIBC pts, along with biomarker analysis. All enrolled pts underwent RC after treatment, with $42 \%$ showing pathological complete response (pT0). This response was significantly enriched in pts with PD-L1 combined positive score (CPS) $\geq 10 \%$. Pembrolizumab was well tolerated with few immune-related adverse events (AEs). Interestingly, pT0 was associated with DNA damage response (DDR) gene alterations and high tumor mutational burden (TMB), suggesting a predictive role of these two biomarkers.

Consistently with these results, anti-PDL1 Atezolizumab showed interesting outcomes as a neoadjuvant treatment for MIBC in the ABACUS trial [55], with a pathological complete response rate of $29 \%$ (95\% CI: $18-42 \%$ ) and good safety. In fact, grade 3-5 AEs occurred only in $11 \%(10 / 95)$ of pts treated with atezolizumab [71].

Anti-PD1 Nivolumab and anti-CTLA4 Ipilimumab combination was also assessed in preoperative setting in the NABUCCO trial [72]. A complete response was observed in $46 \%$ of pts, irrespective of pre-existing $\mathrm{CD}^{+} \mathrm{T}$ cell activity. Moreover, DUTRENEO [73] and MDACC [74] trials aimed to assess the Durvalumab plus Tremelimumab activity before RC. In the former trial, pts were selected according to tumor immune score (TIS) and randomized to receive standard CT or combination with Durvalumab + Tremelimumab. The immunotherapy group showed a complete pathological response rate of $34.8 \%$, with a safe profile. However, TIS did not seem to correlate with the response in this group.

The phase II BLASST trial [75] tested the Nivolumab and GC combination as neoadjuvant treatment for MIBC. A complete pathological response was observed in $65.8 \%$ of pts, including those with N1 disease, and grade $3-4$ AEs in $20 \%$ of study population, mostly from GC.

Finally, the phase 3 trial ENERGIZE [76] evaluated the efficacy and safety of GC alone or with Nivolumab or Nivolumab + Linrodostat (an IDO1 inhibitor) in the neoadjuvant setting. The blockade of these two pathways could be a solid alternative in cisplatinineligible pts. Table 2 summarizes the main trials evaluating neoadjuvant immunotherapy for BC. 
Table 2. Summary of trials using immunotherapy in neoadjuvant setting.

\begin{tabular}{|c|c|c|c|c|c|c|c|c|}
\hline Trial Name & Phase & Drug & Regimen & Elegible Pts & Sample Size & pCR Rate/pCR Rate PD-L1+ & DFS/DFS PD-L1+ & OS \\
\hline PURE-01 & 2 & Pembrolizumab & 3 cycles & $\begin{array}{c}\text { Elegible and } \\
\text { ineligible for CDDP }\end{array}$ & $143 \mathrm{pts}$ & $55 \% / 54.3 \%$ & 1 y DFS $84 \%$ & 1 y OS $91 \%$ \\
\hline ABACUS & 2 & Atezolizumab & 2 cycles & Ineligible for CDDP & $88 \mathrm{pts}$ & $27 \% / 37 \%$ & $79 \% / 75-95 \%$ & NA \\
\hline NABUCCO & 2 & Nivolumab + Ipilimumab & 2 cycles & $\begin{array}{l}\text { Ineligible or refused } \\
\text { CDDP }\end{array}$ & 24 pts & $11 \% / 73 \%$ & NA & NA \\
\hline DUTRENEO & 2 & $\begin{array}{l}\text { Durvalumab + Tremelimumab vs. CT } \\
\quad(\text { Gem + CDDP or MVACdd })\end{array}$ & 3 cycles & Elegible for CDDP & 61 pts (enrolling) & $\begin{array}{c}36,4 \% \text { vs. } 34.8 \% \\
\text { /PDL1 high } \\
57.1 \% \text { vs. } 60 \% / \text { PDL1 low } \\
14.3 \% \text { vs. } 60 \%\end{array}$ & NA & NA \\
\hline MDACC & 1 & Durvalumab + Tremelimumab & $\begin{array}{c}\text { Du }+ \text { Tre } \times 2 \text { clycles OR } \\
\text { Du }+ \text { Tre } \times 1 \text { cycles } \\
\rightarrow \text { Du } \times 1 \text { cycles }\end{array}$ & CDDP ineligible & 28 pts (enrolling) & $37.5 \%$ & NA & NA \\
\hline BLASST & 2 & Nivolumab + CDPP + Gem & 4 cycles & Elegible for CDDP & $41 \mathrm{pts}$ & $34 \% / \mathrm{NA}$ & NA & NA \\
\hline ENERGIZE & 3 & $\begin{array}{l}\text { CDDP + Gem vs. CDDP + Gem + } \\
\text { Nivolumab + Placebo vs. CDDP + Gem } \\
\text { + Nivolumab + Linrodostat mesylate }\end{array}$ & $\begin{array}{l}4 \text { clycles OR } 4 \text { clycles } \rightarrow 9 \\
\text { cycles (adjuvant) }\end{array}$ & Elegible for CDDP & 1200 pts (enrolling) & NA & NA & NA \\
\hline
\end{tabular}

Abbreviations: pCR—-pathological complete response; DFS—disease free survival; OS—overall survival; pts—patients; CDDP—cisplatin; ddMAVC—dose-dense M-VAC (methotrexate, vinblastine sulfate, adriamycin, and cisplatin; NA—not available; Du—Durvalumab; Tre-Tremelimumab. 


\section{Discussion and Conclusions}

Neoadjuvant platinum-based chemotherapy represents the standard treatment for non-metastatic MIBC [77]. However, cisplatin-ineligible pts could not benefit from a systemic therapy before surgery, with a high risk of relapse after RC. In this scenario, many trials evaluating the role of ICIs have shown promising results. Despite the good outcomes considering $\mathrm{pCR}$ and OS/PFS, pts that could benefit from this treatment have not been identified yet. As a consequence, molecular biomarkers for patient's selection are needed. As described before, many trials investigated the role of PD-L1 or TMB with promising evidence.

DDR alterations have been correlated to immunotherapy response in several cancer types. Considering that BC is highly reliant on DDR alterations and activation of genes involved in intrinsic DNA damage and replication stress (such as p53 and $\mathrm{Rb}$ ), we foresee that BC could be an ideal setting to test combinations/sequence of chemotherapy or DDR targeting agents or radiotherapy with immunotherapy in order to increase antitumor immune response. However, further investigations are needed to verify the efficacy of this approach.

The rational for these combinations is based on the ability of cancer cells with high intrinsic or treatment-induced DNA damage to activate an innate immune response via STING (Stimulator of interferon response), as demonstrated in other cancer types [78,79].

In this context, we speculate that circulating tumor DNA (ctDNA) analysis could be useful to identify valid biomarkers, as emerged from the Imvigor010 trial [80,81]. However, data from the ctDNA analysis showed interesting results [82]. ctDNA levels have been used as valid predictors of complete tumor response in multiple cancer types [83]. Pts positive for ctDNA show higher OS and PFS in the immunotherapy arm than the observation arm (DFS HR, 0.58 (95\% CI: 0.43-0.79) $p=0.0024$; OS HR, 0.59 (95\% CI: 0.41-0.86)) [82]. In conclusion, these results could be useful to modify clinical practice in the neoadjuvant setting, although further clinical trials and evaluation of molecular biomarkers are needed for better pts' selection.

Author Contributions: Study design, M.L.I., B.B., C.C.M., M.D.F., L.P., F.C. (Francesco Chiancone), E.D.Z., G.T., C.M.D.C., F.C. (Felice Crocetto); data curation, M.L.I., B.B., C.C.M., M.D.F., L.P., F.C. (Francesco Chiancone), E.D.Z., G.T., C.M.D.C., F.C. (Felice Crocetto); writing-original draft preparation, M.L.I., B.B., C.C.M., M.D.F.; writing-review and editing, all authors; project administration, C.I., F.D.V., F.C. (Felice Crocetto). All authors have read and agreed to the published version of the manuscript.

Funding: This research received no external funding.

Institutional Review Board Statement: Not applicable.

Informed Consent Statement: Not applicable.

Data Availability Statement: Not applicable.

Conflicts of Interest: The authors declare no conflict of interest.

\section{References}

1. Saginala, K.; Barsouk, A.; Aluru, J.S.; Rawla, P.; Padala, S.A.; Barsouk, A. Epidemiology of bladder cancer. Med. Sci. 2020, 8, 15. [CrossRef] [PubMed]

2. Alifrangis, C.; McGovern, U.; Freeman, A.; Powles, T.; Linch, M. Molecular and histopathology directed therapy for advanced bladder cancer. Nat. Rev. Urol. 2019, 16, 465-483. [CrossRef] [PubMed]

3. Zhu, S.; Yu, W.; Yang, X.; Wu, C.; Cheng, F. Traditional Classification and Novel Subtyping Systems for Bladder Cancer. Front. Oncol. 2020, 10, 102. [CrossRef] [PubMed]

4. Tsao, C.K.; Liaw, B.C.; Oh, W.K.; Galsky, M.D. Muscle invasive bladder cancer: Closing the gap between practice and evidence. Minerva Urol. Nefrol. 2014, 67, 65-73. [PubMed]

5. Witjes, J.A.; Bruins, H.M.; Cathomas, R.; Compérat, E.M.; Cowan, N.C.; Gakis, G.; Hernández, V.; Linares Espinós, E.; Lorch, A.; Neuzillet, Y.; et al. European Association of Urology Guidelines on Muscle-invasive and Metastatic Bladder Cancer: Summary of the 2020 Guidelines. Eur. Urol. 2021, 79, 82-104. [CrossRef] 
6. Milowsky, M.I.; Rumble, R.B.; Booth, C.M.; Gilligan, T.; Eapen, L.J.; Hauke, R.J.; Boumansour, P.; Lee, C.T. Guideline on MuscleInvasive and Metastatic Bladder Cancer (European Association of Urology Guideline): American Society of Clinical Oncology Clinical Practice Guideline Endorsement. J. Clin. Oncol. 2016, 34, 1945-1952. [CrossRef]

7. Galsky, M.D.; Hahn, N.M.; Rosenberg, J.; Sonpavde, G.; Hutson, T.; Oh, W.K.; Dreicer, R.; Vogelzang, N.; Sternberg, C.; Bajorin, D.F.; et al. A consensus definition of pts with metastatic urothelial carcinoma who are unfit for cisplatin-based chemotherapy. Lancet Oncol. 2011, 12, 211-214. [CrossRef]

8. Bhindi, B.; Frank, I.; Mason, R.J.; Tarrell, R.F.; Thapa, P.; Cheville, J.C.; Costello, B.A.; Pagliaro, L.C.; Karnes, R.J.; Thompson, R.H.; et al. Oncologic Outcomes for Pts with Residual Cancer at Cystectomy Following Neoadjuvant Chemotherapy: A Pathologic Stage-matched Analysis. Eur. Urol. 2017, 72, 660-664. [CrossRef]

9. Cancer Genome Atlas Research Network. Comprehensive molecular characterization of urothelial bladder carcinoma. Nature 2014, 507, 315-322. [CrossRef]

10. Pietzak, E.J.; Zabor, E.C.; Bagrodia, A.; Armenia, J.; Hu, W.; Zehir, A.; Funt, S.; Audenet, F.; Barron, D.; Maamouri, N.; et al. Genomic differences between "primary" and "secondary" muscle-invasive bladder cancer as a basis for disparate outcomes to cisplatin-based neoadjuvant chemotherapy. Eur. Urol. 2019, 75, 231-239. [CrossRef]

11. Robertson, A.G.; Kim, J.; Al-Ahmadie, H.; Bellmunt, J.; Guo, G.; Cherniack, A.D.; Hinoue, T.; Laird, P.W.; Hoadley, K.A.; Akbani, R.; et al. Comprehensive Molecular Characterization of Muscle-Invasive Bladder Cancer. Cell 2017, 171, 540-556. [CrossRef]

12. Loriot, Y.; Necchi, A.; Park, S.H.; Garcia-Donas, J.; Huddart, R.; Burgess, E.; Fleming, M.; Rezazadeh, A.; Mellado, B.; Varlamov, S.; et al. Erdafitinib in Locally Advanced or Metastatic Urothelial Carcinoma. N. Engl. J. Med. 2019, 381, 338-348. [CrossRef]

13. Guinney, J.; Dienstmann, R.; Wang, X.; De Reynies, A.; Schlicker, A.; Soneson, C.; Marisa, L.; Roepman, P.; Nyamundanda, G.; Angelino, P.; et al. The consensus molecular subtypes of colorectal cancer. Nat. Med. 2015, 21, 1350-1356. [CrossRef]

14. Kamoun, A.; de Reyniès, A.; Allory, Y.; Sjödahl, G.; Robertson, A.G.; Seiler, R.; Hoadley, K.A.; Groeneveld, C.S.; Al-Ahmadie, H.; Choi, W.; et al. A consensus molecular classification of muscle-invasive bladder cancer. Eur. Urol. 2020, 77, 420-433. [CrossRef]

15. Aragon-Ching, J.B.; Werntz, R.P.; Zietman, A.L.; Steinberg, G.D. Multidisciplinary Management of Muscle-Invasive Bladder Cancer: Current Challenges and Future Directions. Am. Soc. Clin. Oncol. Educ. Book 2018, 38, 307-318. [CrossRef]

16. Harshman, L.C.; Preston, M.A.; Bellmunt, J.; Beard, C. Diagnosis of Bladder Carcinoma: A Clinician's Perspective. Surg. Pathol. Clin. 2015, 8, 677-685. [CrossRef]

17. Sun, M.; Trinh, Q.-D. Diagnosis and Staging of Bladder Cancer. Hematol. Clin. N. Am. 2015, 29, 205-218. [CrossRef]

18. Lawrentschuk, N.; Lee, S.T.; Scott, A.M. Current Role of PET, CT, MR for Invasive Bladder Cancer. Curr. Urol. Rep. 2013, 14, 84-89. [CrossRef]

19. Moschini, M.; Shariat, S.F.; Rouprêt, M.; De Santis, M.; Bellmunt, J.; Sternberg, C.N.; Tombal, B.; Collette, L. Impact of Primary Tumor Location on Survival from the European Organization for the Research and Treatment of Cancer Advanced Urothelial Cancer Studies. J. Urol. 2018, 199, 1149-1157. [CrossRef]

20. Van Der Pol, C.B.; Sahni, V.A.; Eberhardt, S.C.; Oto, A.; Akin, O.; Alexander, L.F.; Allen, B.C.; Coakley, F.V.; Froemming, A.T.; Fulgham, P.F.; et al. ACR Appropriateness Criteria ${ }^{\circledR}$ Pretreatment Staging of Muscle-Invasive Bladder Cancer. J. Am. Coll. Radiol. 2018, 15, S150-S159. [CrossRef]

21. Mirmomen, S.M.; Shinagare, A.B.; Williams, K.E.; Silverman, S.G.; Malayeri, A.A. Preoperative imaging for locoregional staging of bladder cancer. Abdom. Radiol. 2019, 44, 3843-3857. [CrossRef]

22. Green, D.A.; Durand, M.; Gumpeni, N.; Rink, M.; Cha, E.K.; Karakiewicz, P.I.; Scherr, D.S.; Shariat, S.F. Role of magnetic resonance imaging in bladder cancer: Current status and emerging techniques. BJU Int. 2012, 110, 1463-1470. [CrossRef]

23. Yoshida, S.; Koga, F.; Kobayashi, S.; Ishii, C.; Tanaka, H.; Tanaka, H.; Komai, Y.; Saito, K.; Masuda, H.; Fujii, Y.; et al. Role of diffusion-weighted magnetic resonance imaging in predicting sensitivity to chemoradiotherapy in muscle-invasive bladder cancer. Int. J. Radiat. Oncol. Biol. Phys. 2012, 83, e21-e27. [CrossRef]

24. Necchi, A.; Bandini, M.; Calareso, G.; Raggi, D.; Pederzoli, F.; Fare, E.; Colecchia, M.; Marandino, L.; Bianchi, M.; Gallina, A.; et al. Multiparametric Magnetic Resonance Imaging as a Noninvasive Assessment of Tumor Response to Neoadjuvant Pembrolizumab in Muscle-Invasive Bladder Cancer: Preliminary Findings from the PURE-01 Study. Eur. Urol. 2020, 77, 636-643. [CrossRef] [PubMed]

25. Nguyen, H.T.; Jia, G.; Shah, Z.; Pohar, K.; Mortazavi, A.; Zynger, D.L.; Wei, L.; Yang, X.; Clark, D.; Knopp, M.V. Prediction of chemotherapeutic response in bladder cancer using K-means clustering of dynamic contrast enhanced (DCE)-MRI pharmacokinetic parameters. J. Magn. Reson. Imaging 2015, 41, 1374-1382. [CrossRef] [PubMed]

26. Alongi, P.; Caobelli, F.; Gentile, R.; Stefano, A.; Russo, G.; Albano, D.; Baldari, S.; Gilardi, M.C.; Midiri, M. Recurrent bladder carcinoma: Clinical and prognostic role of 18 F-FDG PET/CT. Eur. J. Nucl. Med. Mol. Imaging 2016, 44, 224-233. [CrossRef] [PubMed]

27. Ghandour, R.; Singla, N.; Lotan, Y. Treatment Options and Outcomes in Nonmetastatic Muscle Invasive Bladder Cancer. Trends Cancer 2019, 5, 426-439. [CrossRef] [PubMed]

28. Schag, C.C.; Heinrich, R.L.; Ganz, P.A. Karnofsky performance status revisited: Reliability, validity, and guidelines. J. Clin. Oncol. 1984, 2, 187-193. [CrossRef] 
29. Yin, M.; Joshi, M.; Meijer, R.P.; Glantz, M.; Holder, S.; Harvey, H.A.; Kaag, M.; Van De Putte, E.E.F.; Horenblas, S.; Drabick, J.J. Neoadjuvant Chemotherapy for Muscle-Invasive Bladder Cancer: A Systematic Review and Two-Step Meta-Analysis. Oncologist 2016, 21, 708-715. [CrossRef]

30. Leow, J.J.; Bedke, J.; Chamie, K.; Collins, J.W.; Daneshmand, S.; Grivas, P.; Heidenreich, A.; Messing, E.M.; Royce, T.J.; Sankin, A.I.; et al. SIU-ICUD consultation on bladder cancer: Treatment of muscle-invasive bladder cancer. World J. Urol. 2019, 37, 61-83. [CrossRef]

31. Advanced Bladder Cancer (ABC) Meta-analysis Collaboration. Neoadjuvant chemotherapy in invasive bladder cancer: Update of a systematic review and meta-analysis of individual patient data advanced bladder cancer (ABC) meta-analysis collaboration. Eur. Urol. 2005, 48, 202-205; discussion 205-206. [CrossRef]

32. Grossman, H.B.; Natale, R.B.; Tangen, C.M.; Speights, V.; Vogelzang, N.J.; Trump, D.L.; White, R.W.D.; Sarosdy, M.F.; Wood, D.P.; Raghavan, D.; et al. Neoadjuvant chemotherapy plus cystectomy compared with cystectomy alone for locally advanced bladder cancer. N. Engl. J. Med. 2003, 349, 859-866. [CrossRef]

33. Sengeløv, L.; Von Der Maase, H.; Lundbeck, F.; Barlebo, H.; Colstrup, H.; Engelholm, S.; Krarup, T.; Madsen, E.; Meyhoff, H.; Mommsen, S.; et al. Neoadjuvant chemotherapy with cisplatin and methotrexate in pts with muscle-invasive bladder tumours. Acta Oncol. 2002, 41, 447-456. [CrossRef]

34. Sherif, A.; Rintala, E.; Mestad, O.; Nilsson, J.; Holmberg, L.; Nilsson, S.; Malmström, P.-U. Neoadjuvant cisplatin-methotrexate chemotherapy for invasive bladder cancer-Nordic cystectomy trial 2. Scand. J. Urol. Nephrol. 2002, 36, 419-425. [CrossRef]

35. Bassi, P.F.; Pappagallo, G.L.; Sperandio, P.; Monfardini, S.; Pagano, F.; Cosciani, S.; Lembo, A.; Anselmo, G.; Signorelli, G.; Lavelli, D. Neoadjuvant MVAC chemotherapy of invasive bladder cancer: Results of a multicenter phase III trial. J. Urol. 1999, 161, 264. [CrossRef]

36. International Collaboration of Trialists. Neoadjuvant cisplatin, methotrexate, and vinblastine chemotherapy for muscle-invasive bladder cancer: A randomised controlled trial. Lancet 1999, 354, 533-540. [CrossRef]

37. Sternberg, C.N.; de Mulder, P.; Schornagel, J.H.; Theodore, C.; Fossa, S.; van Oosterom, A.; Witjes, J.; Spina, M.; van Groeningen, C.; Duclos, B.; et al. Seven year update of an EORTC phase III trial of high-dose intensity M-VAC chemotherapy and G-CSF versus classic M-VAC in advanced urothelial tract tumours. Eur. J. Cancer 2006, 42, 50-54. [CrossRef]

38. Choueiri, T.K.; Jacobus, S.; Bellmunt, J.; Qu, A.; Appleman, L.; Tretter, C.; Bubley, G.J.; Stack, E.C.; Signoretti, S.; Walsh, M.; et al. Neoadjuvant dose-dense methotrexate, vinblastine, doxorubicin, and cisplatin with pegfilgrastim support in muscle-invasive urothelial cancer: Pathologic, radiologic, and biomarker correlates. J. Clin. Oncol. 2014, 32, 1889-1894. [CrossRef]

39. Roberts, J.T.; Von Der Maase, H.; Sengeløv, L.; Conte, P.F.; Dogliotti, L.; Oliver, T.; Moore, M.J.; Zimmermann, A.; Arning, M. Longterm survival results of a randomized trial comparing gemcitabine/cisplatin and methotrexate/vinblastine/doxorubicin/cisplatin in pts with locally advanced and metastatic bladder cancer. Ann. Oncol. 2006, 17 (Suppl. 5), v118-v122. [CrossRef]

40. Galsky, M.D.; Pal, S.K.; Chowdhury, S.; Harshman, L.C.; Crabb, S.; Wong, Y.-N.; Yu-Ning, W.; Powles, T.; Moshier, E.L.; Ladoire, S.; et al. Comparative effectiveness of gemcitabine plus cisplatin versus methotrexate, vinblastine, doxorubicin, plus cisplatin as neoadjuvant therapy for muscle-invasive bladder cancer. Cancer 2015, 121, 2586-2593. [CrossRef]

41. Zargar, H.; Shah, J.B.; Van Rhijn, B.W.; Daneshmand, S.; Bivalacqua, T.J.; Spiess, P.E.; Black, P.C.; Kassouf, W. Neoadjuvant dose dense MVAC versus gemcitabine and cisplatin in pts with cT3- 4aN0M0 bladder cancer treated with radical cystectomy. J. Urol. 2018, 199, 1452-1458. [PubMed]

42. Pfister, C.; Gravis, G.; Flechon, A.; Chevreau, C.M.; Mahammedi, H.; Laguerre, B.; Guillot, A.; Joly, F.; Soulie, M.; Allory, Y.; et al. $652 \mathrm{O}$ Dose-dense methotrexate vinblastine, doxorubicin and cisplatin (dd-MVAC) or gemcitabine and cisplatin (GC) as perioperative chemotherapy for pts with muscle-invasive bladder cancer (MIBC): Results of the GETUG/AFU VESPER V05 phase III trial. Ann. Oncol. 2021, 32, S678. [CrossRef]

43. Pfister, C.; Gravis, G.; Fléchon, A.; Soulié, M.; Guy, L.; Laguerre, B.; Mottet, N.; Joly, F.; Allory, Y.; Harter, V.; et al. Randomized Phase III Trial of Dose-dense Methotrexate, Vinblastine, Doxorubicin, and Cisplatin, or Gemcitabine and Cisplatin as Perioperative Chemotherapy for Pts with Muscle-invasive Bladder Cancer. Analysis of the GETUG/AFU V05 VESPER Trial Secondary Endpoints: Chemotherapy Toxicity and Pathological Responses. Eur. Urol. 2021, 79, 222-224.

44. Ferro, M.; de Cobelli, O.; Musi, G.; Lucarelli, G.; Terracciano, D.; Pacella, D.; Muto, T.; Porreca, A.; Busetto, G.M.; Del Giudice, F.; et al. Three vs. Four Cycles of Neoadjuvant Chemotherapy for Localized Muscle Invasive Bladder Cancer Undergoing Radical Cystectomy: A Retrospective Multi-Institutional Analysis. Front. Oncol. 2021, 11, 651745. [CrossRef]

45. Siefker-Radtke, A.O.; Dinney, C.P.; Shen, Y.; Williams, D.L.; Kamat, A.M.; Grossman, H.B.; Millikan, R.E. A phase 2 clinical trial of sequential neoadjuvant chemotherapy with ifosfamide, doxorubicin, and gemcitabine followed by cisplatin, gemcitabine, and ifosfamide in locally advanced urothelial cancer: Final results. Cancer 2013, 119, 540-547. [CrossRef]

46. Fahmy, N.M.; Mahmud, S.; Aprikian, A.G. Delay in the surgical treatment of bladder cancer and survival: Systematic review of the literature. Eur. Urol. 2006, 50, 1176-1182.

47. Bruins, H.M.; Aben, K.K.H.; Arends, T.J.; van der Heijden, A.G.; Witjes, A.J. The effect of the time interval between diagnosis of muscle-invasive bladder cancer and radical cystectomy on staging and survival: A Netherlands Cancer Registry analysis. Urol. Oncol. 2016, 34, 166.e1-166.e6. [CrossRef]

48. Scafuri, L.; Sciarra, A.; Crocetto, F.; Ferro, M.; Buonerba, C.; Ugliano, F.; Guerra, G.; Sanseverino, R.; Di Lorenzo, G. Does perioperative systemic therapy represent the optimal therapeutic paradigm in organ-confined muscle-invasive urothelial carcinoma? Future Sci. OA 2021, 7, FSO770. [CrossRef] 
49. Ferro, M.; Lucarelli, G.; de Cobelli, O.; Dolce, P.; Terracciano, D.; Musi, G.; Porreca, A.; Busetto, G.M.; Del Giudice, F.; Soria, F.; et al. A risk-group classification model in pts with bladder cancer under neoadjuvant cisplatin-based combination chemotherapy. Future Oncol. 2021, 17, 3987-3994. [CrossRef]

50. Ferro, M.; Lucarelli, G.; Crocetto, F.; Dolce, P.; Verde, A.; La Civita, E.; Zappavigna, S.; de Cobelli, O.; Di Lorenzo, G.; Facchini, B.A.; et al. First-line systemic therapy for metastatic castration-sensitive prostate cancer: An updated systematic review with novel findings. Crit. Rev. Oncol. Hematol. 2021, 157, 103198. [CrossRef]

51. Buonerba, C.; Ferro, M.; Dolce, P.; Crocetto, F.; Verde, A.; Lucarelli, G.; Scafuri, L.; Facchini, S.; Vaia, A.; Marinelli, A.; et al. Predictors of efficacy of androgen-receptor-axis-targeted therapies in pts with metastatic castration-sensitive prostate cancer: A systematic review and meta-analysis. Crit. Rev. Oncol. Hematol. 2020, 151, 102992. [CrossRef]

52. Gandaglia, G.; Popa, I.; Abdollah, F.; Schiffmann, J.; Shariat, S.F.; Briganti, A.; Montorsi, F.; Trinh, Q.; Karakiewicz, P.; Sun, M. The effect of neoadjuvant chemotherapy on perioperative outcomes in pts who have bladder cancer treated with radical cystectomy: A population-based study. Eur. Urol. 2014, 66, 561-568. [CrossRef]

53. Tyson, M.D.; Bryce, A.H.; Ho, T.H.; Carballido, E.M.; Castle, E.P. Perioperative complications after neoadjuvant chemotherapy and radical cystectomy for bladder cancer. Can. J. Urol. 2014, 21, 7259-7265.

54. Bada, M.; Crocetto, F.; Creta, M.; Silvestri, T.; Di Mauro, M.; Celia, A. Laparoscopic radical cystectomy with extracorporeal urinary diversion: An Italian single center experience with 10-year outcomes. Minerva Urol. Nefrol. Ital. J. Urol. Nephrol. 2020, 72, 641-643. [CrossRef]

55. Powles, T.; Kockx, M.; Rodriguez-Vida, A.; Duran, I.; Crabb, S.J.; Van Der Heijden, M.S.; Szabados, B.; Pous, A.F.; Gravis, G.; Herranz, U.A.; et al. Clinical efficacy and biomarker analysis of neoadjuvant atezolizumab in operable urothelial carcinoma in the ABACUS trial. Nat. Med. 2019, 25, 1706-1714. [CrossRef]

56. Necchi, A.; Anichini, A.; Raggi, D.; Briganti, A.; Massa, S.; Lucianò, R.; Colecchia, M.; Giannatempo, P.; Mortarini, R.; Bianchi, M.; et al. Pembrolizumab as neoadjuvant therapy before radical cystectomy in pts with muscle-invasive urothelial bladder carcinoma (PURE-01): An open-label single-arm, phase II study. J. Clin. Oncol. 2018, 36, 3353-3360. [CrossRef]

57. Scosyrev, E.; Ely, B.W.; Messing, E.M.; Speights, V.O.; Grossman, H.B.; Wood, D.P.; de Vere White, R.W.; Vogelzang, N.J.; Trump, D.L.; Natale, R.B.; et al. Do mixed histological features affect survival benefit from neoadjuvant platinum-based combination chemotherapy in pts with locally advanced bladder cancer? A secondary analysis of Southwest Oncology GroupDirected Intergroup Study (S8710). BJU Int. 2011, 108, 693-699.

58. Kaimakliotis, H.Z.; Monn, M.F.; Cho, J.S.; Pedrosa, J.A.; Hahn, N.M.; Albany, C.; Gellhaus, P.T.; Cary, K.C.; Masterson, T.A.; Foster, R.S.; et al. Neoadjuvant chemotherapy in urothelial bladder cancer: Impact of regimen and variant histology. Future Oncol. 2016, 12, 1795-1804. [CrossRef]

59. Abufaraj, M.; Foerster, B.; Schernhammer, E.; Moschini, M.; Kimura, S.; Hassler, M.R.; Preston, M.A.; Karakiewicz, P.I.; Remzi, M.; Shariat, S.F. Micropapillary urothelial carcinoma of the bladder: A systematic review and meta-analysis of disease characteristics and treatment outcomes. Eur. Urol. 2019, 75, 649-658. [CrossRef]

60. Dayyani, F.; Czerniak, B.A.; Sircar, K.; Munsell, M.F.; Millikan, R.E.; Dinney, C.P.; Siefker-Radtke, A. Plasmacytoid urothelial carcinoma, a chemosensitive cancer with poor prognosis, and peritoneal carcinomatosis. J. Urol. 2013, 189, 1656-1661. [CrossRef]

61. Dadhania, V.; Czerniak, B.; Guo, C.C. Adenocarcinoma of the urinary bladder. Am. J. Clin. Exp. Urol. 2015, 3, 51-63. [PubMed]

62. Drake, C.G.; Jaffee, E.; Pardoll, D.M. Mechanisms of immune evasion by tumors. Adv. Immunol. 2006, 90, 51-81. [PubMed]

63. Ribas, A.; Wolchok, J.D. Cancer immunotherapy using checkpoint blockade. Science 2018, 359, 1350-1355. [CrossRef] [PubMed]

64. Buonerba, C.; Dolce, P.; Iaccarino, S.; Scafuri, L.; Verde, A.; Costabile, F.; Pagliuca, M.; Morra, R.; Riccio, V.; Ribera, D.; et al. Outcomes Associated with First-Line anti-PD-1/ PD-L1 agents vs. Sunitinib in Pts with Sarcomatoid Renal Cell Carcinoma: A Systematic Review and Meta-Analysis. Cancers 2020, 12, 408. [CrossRef]

65. Hui, E. Immune checkpoint inhibitors. J. Cell Biol. 2019, 218, 740-741. [CrossRef]

66. Wei, S.C.; Duffy, C.R.; Allison, J.P. Fundamental mechanisms of immune checkpoint blockade therapy. Cancer Discov. 2018, 8, 1069-1086. [CrossRef]

67. Bellmunt, J.; De Wit, R.; Vaughn, D.J.; Fradet, Y.; Lee, J.L.; Fong, L.; Vogelzang, N.J.; Climent, M.A.; Petrylak, D.P.; Choueiri, T.K.; et al. Pembrolizumab as second-line therapy for advanced urothelial carcinoma. N. Engl. J. Med. 2017, 376, 1015-1026. [CrossRef]

68. Balar, A.V.; Castellano, D.; O’Donnell, P.H.; Grivas, P.; Vuky, J.; Powles, T.; Plimack, E.R.; Hahn, N.M.; de Wit, R.; Pang, L.; et al. First-line pembrolizumab in cisplatin-ineligible pts with locally advanced and unresectable or metastatic urothelial cancer (KEYNOTE-052): A multicentre, single-arm, phase 2 study. Lancet Oncol. 2017, 18, 1483-1492. [CrossRef]

69. Powles, T.; Park, S.H.; Voog, E.; Caserta, C.; Valderrama, B.P.; Gurney, H.; Kalofonos, H.; Radulović, S.; Demey, W.; Ullén, A.; et al. Avelumab maintenance therapy for advanced or metastatic urothelial carcinoma. N. Engl. J. Med. 2020, 383, 1218-1230. [CrossRef]

70. Rey-Cárdenas, M.; Guerrero-Ramos, F.; de Liaño Lista, A.G.; Carretero-González, A.; Bote, H.; Herrera-Juárez, M.; Carril-Ajuria, L.; Martín-Soberón, M.; Sepulveda, J.; Billalabeitia, E.; et al. Recent advances in neoadjuvant immunotherapy for urothelial bladder cancer: What to expect in the near future. Cancer Treat. Rev. 2021, 93, 102142. [CrossRef]

71. Szabados, B.; Rodriguez-Vida, A.; Durán, I.; Crabb, S.J.; Van Der Heijden, M.S.; Pous, A.F.; Gravis, G.; Herranz, U.A.; Protheroe, A.; Ravaud, A.; et al. Toxicity and Surgical Complication Rates of Neoadjuvant Atezolizumab in Pts with Muscle-invasive Bladder Cancer Undergoing Radical Cystectomy: Updated Safety Results from the ABACUS Trial. Eur. Urol. Oncol. 2021, 4, 456-463. [CrossRef] 
72. $\quad$ van Dijk, N.; Gil-Jimenez, A.; Silina, K.; Hendricksen, K.; Smit, L.A.; de Feijter, J.M.; van Montfoort, M.L.; van Rooijen, C.; Peters, D.; Broeks, A.; et al. Preoperative ipilimumab plus nivolumab in locoregionally advanced urothelial cancer: The NABUCCO trial. Nat. Med. 2020, 26, 1839-1844. [CrossRef]

73. Grande, E.; Guerrero, F.; Puente, J.; Galante, I.; Duran, I.; Dominguez, M.; Gordoa, T.A.; Burgos, J.; Font, A.; Pinto, A.; et al. DUTRENEO Trial: A randomized phase II trial of DUrvalumab and TREmelimumab versus chemotherapy as a NEOadjuvant approach to muscle-invasive urothelial bladder cancer (MIBC) pts (pts) prospectively selected by an interferon (INF)-gamma immune signature. J. Clin. Oncol. 2020, 38, 5012. [CrossRef]

74. Gao, J.; Navai, N.; Alhalabi, O.; Siefker-Radtke, A.; Campbell, M.T.; Tidwell, R.S.; Guo, C.; Kamat, A.M.; Matin, S.F.; Araujo, J.C.; et al. Neoadjuvant PD-L1 plus CTLA-4 blockade in pts with cisplatin-ineligible operable high-risk urothelial carcinoma. Nat. Med. 2020, 26, 1845-1851. [CrossRef]

75. Gupta, S.; Sonpavde, G.; Weight, C.J.; McGregor, B.A.; Gupta, S.; Maughan, B.L.; Wei, X.X.; Gibb, E.; Thyagarajan, B.; Einstein, D.J.; et al. Results from BLASST-1 (Bladder Cancer Signal Seeking Trial) of nivolumab, gemcitabine, and cisplatin in muscle invasive bladder cancer (MIBC) undergoing cystectomy. J. Clin. Oncol. 2020, 38, 4392020. [CrossRef]

76. Sonpavde, G.; Necchi, A.; Gupta, S.; Steinberg, G.D.; Gschwend, J.E.; Van Der Heijden, M.S.; Garzon, N.; Ibrahim, M.; Raybold, B.; Liaw, D.; et al. ENERGIZE: A Phase III study of neoadjuvant chemotherapy alone or with nivolumab with/without linrodostat mesylate for muscle-invasive bladder cancer. Future Oncol. 2020, 16, 4359-4368. [CrossRef]

77. Tarantino, G.; Crocetto, F.; Di Vito, C.; Creta, M.; Martino, R.; Pandolfo, S.D.; Pesce, S.; Napolitano, L.; Capone, D.; Imbimbo, C. Association of NAFLD and Insulin Resistance with Non Metastatic Bladder Cancer Patients: A Cross-Sectional Retrospective Study. J. Clin. Med. 2021, 10, 346. [CrossRef]

78. Della Corte, C.M.; Sen, T.; Gay, C.M.; Ramkumar, K.; Diao, L.; Cardnell, R.J.; Rodriguez, B.L.; Stewart, C.A.; Papadimitrakopoulou, V.A.; Gibson, L.; et al. STING pathway expression identifies NSCLC with an immune-responsive phenotype. J. Thorac. Oncol. 2020, 15, 777-791. [CrossRef]

79. Du, H.; Xu, T.; Cui, M. cGAS-STING signaling in cancer immunity and immunotherapy. Biomed. Pharmacother. 2021, $133,110972$. [CrossRef]

80. Busetto, G.M.; Porreca, A.; Del Giudice, F.; Maggi, M.; D’Agostino, D.; Romagnoli, D.; Musi, G.; Lucarelli, G.; Palmer, K.; Di Paliano, A.C.; et al. SARS-CoV-2 Infection and High-Risk Non-Muscle-Invasive Bladder Cancer: Are There Any Common Features? Urol. Int. 2020, 104, 510-522. [CrossRef]

81. Bellmunt, J.; Hussain, M.; Gschwend, J.E.; Albers, P.; Oudard, S.; Castellano, D.; Daneshmand, S.; Nishiyama, H.; Majchrowicz, M.; IMvigor010 Study Group. Adjuvant atezolizumab versus observation in muscle-invasive urothelial carcinoma (IMvigor010): A multicentre, open-label, randomised, phase 3 trial. Lancet Oncol. 2021, 22, 525-537. [CrossRef]

82. Powles, T.B.; Assaf, Z.J.; Davarpanah, N.; Hussain, M.; Oudard, S.; Gschwend, J.E.; Albers, P.; Castellano, D.; Nishiyama, H.; Daneshmand, S.; et al. $1 \mathrm{O}$ Clinical outcomes in post-operative ctDNA-positive muscle-invasive urothelial carcinoma (MIUC) pts after atezolizumab adjuvant therapy. Ann. Oncol. 2020, 31, S1417. [CrossRef]

83. Cheng, M.L.; Pectasides, E.; Hanna, G.J.; Parsons, H.A.; Choudhury, A.D.; Oxnard, G.R. Circulating tumor DNA in advanced solid tumors: Clinical relevance and future directions. CA Cancer J. Clin. 2021, 71, 176-190. [CrossRef] [PubMed] 